\title{
SCANNING AND DATA CAPTURING FOR BIM-SUPPORTED RESOURCES ASSESSMENT: A CASE STUDY
}

SUBMITTED: January 2020

REVISED: February 2021

PUBLISHED: August 2021

GUEST EDITORS: Francis Siu, Hung-Lin Chi, Hsi-hsien Wei \& Minkoo Kim

DOI: $10.36680 /$ j.itcon.2021.032

Iva Kovacic, Prof. Dr.,

TU Wien, Institute for interdisciplinary Building Process Management, Austria;

iva.kovacic@tuwien.ac.at

Meliha Honic, Dr.,

TU Wien, Institute for interdisciplinary Building Process Management, Austria;

meliha.honic@tuwien.ac.at

SUMMARY: Buildings are the largest consumer of raw materials and simultaneously are responsible for $40 \%$ of the global energy consumption as well as for about $30 \%$ of global $\mathrm{CO}_{2}$ emissions. In order to reach sustainability goals such as reduction of the use of primary resources, it is of utmost importance to reuse or recycle the existing stocks - a strategy labelled as "Urban Mining". The fact that the new construction rate is only 3\%, underlines the importance of Urban Mining. However, there is lack of knowledge about the exact material composition and geometry of the existing stock, which represents the main obstacle for Urban Mining and accordingly for reaching high recycling rates.

In this paper the Integrated Data Assessment and Modelling (IDAM) method based on digital scanning and modelling technologies for capturing of the geometry and material composition data is proposed for enabling a generation of as built Building Information Modelling (BIM)-models from acquired point clouds and nongeometric data. The main aim of this research is to explore the potential of the IDAM method for the generation of a BIM-model, which serves as basis for BIM-based Material Passports (MP), as major element enabling Circular Economy $(C E)$ and Urban Mining strategies as well as the creation of a digital secondary raw materials cadastre.

In order to deliver a proof of concept for IDAM, a real use case will be assessed in terms of geometry and material composition, and possibilities of data capturing via laser scanning and ground penetrating radar (GPR) for follow-up generation of a BIM-based MP explored. For capturing the geometry, laser scanning, and for capturing the material composition, GPR is used. The use of GPR for the generation of a BIM-model, which incorporates material information, addresses a research gap - the capturing and modelling of geometry is already well explored, however the methods and tools for capturing and modelling of the material composition of buildings are largely lacking. Result show, that the coupled use of capturing technologies has great potential to serve as basis for a BIM-based MP. Moreover, the use of GPR, enables a determination of embedded materials within a building, but is confronted with various difficulties. As a result, a framework, which can serve as groundwork for follow-up research, is presented.

KEYWORDS: Laser Scanning, Point Cloud, Material Passport, As-built BIM, Ground Penetrating Radar

REFERENCE: Iva Kovacic, Meliha Honic (2021). Scanning and data capturing for BIM-supported resources assessment: a case study. Journal of Information Technology in Construction (ITcon), Special issue: 'CIB World Building Congress 2019: Constructing Smart Cities', Vol. 26, pg. 624-638, DOI: 10.36680/j.itcon.2021.032

COPYRIGHT: ( 2021 The author(s). This is an open access article distributed under the terms of the Creative Commons Attribution 4.0 International (https://creativecommons.org/licenses/by/4.0/), which permits unrestricted use, distribution, and reproduction in any medium, provided the original work is properly cited. 


\section{INTRODUCTION}

Due to worldwide rapidly increasing consumption of resources and land, as well as growing generation of waste, increasing of recycling and reuse rates of materials, next to reduction of energy consumption is of highest priority for achieving sustainability within the Architecture, Engineering and Construction (AEC) industry. The increasing population growth and urbanization simultaneously rises the worldwide consumption of material resources. The challenge of the future will be to provide sufficient material and natural resources, as well as to minimize the continual amount of waste (WEF, 2016). Building stocks and infrastructures are the largest material stocks of industrial economies. These total material stocks on the global scale are about as large as reserves of primary resources in nature (Brunner and Rechberger, 2017). It is of long-term importance to maintain or frequently recycle these urban stocks, and in consequence to minimize the use of primary resources, thus the dependency on imports - a strategy labelled as Urban Mining, which is a part of Circular Economy (CE). For enabling a successful utilisation of the Urban Mining strategy, detailed knowledge about the existing stock and embedded materials is needed, which is currently lacking. Therefore, in order to gain knowledge about the exact material composition of building stocks, as well as enable an assessment, analysis and prediction of material flows, the development of applicable methodologies is urgently needed. Building Information Modelling (BIM) has the potential to support a life-cycle optimization of the built environment (Fellows and Liu, 2012), as it enables modelling, analysis and optimization of new constructions as well as of building stocks. Through coupling of BIM with capturing technologies such as laser scanning and ground penetrating radar (GPR), a thorough assessment of existing stocks can be conducted; and inventories on the detailed material composition of buildings such as Material Passports (MP), generated.

The aim of this paper is to explore the potentials of digital technologies, laser scanning and GPR, and so generated BIM-models serving as basis for the compilation of MPs, which are a supporting instrument for the realization of $\mathrm{CE}$ in the AEC industry. In this paper we will propose a novel method - Integrated Data Assessment and Modelling (IDAM) - based on the material identification via GPR and the generation of an as-built BIM on the basis of scandata (point cloud). IDAM allows the generation of information rich BIM-models, thus providing a comprehensive knowledge base, including both, geometrical and parametric attributes such as layer structures (building materials within building elements) and specific properties regarding BIM-based MPs (e.g. thickness and volume of each material layer).

This paper addresses a research gap - Merging of geometry information (laser scanning) with material information (GPR). Current research mainly deals with the automation of the scan-to-BIM process with focus on the reconstruction of the geometry (Bassier et. al, 2020; Tang et al., 2010; Xiong et al., 2013). Previous work regarding material recognition is either limited to image-based recognition (Ge et al., 2017; Yang et al., 2016), which shows potential for an integration of material data into BIM, but does not deliver sufficient information about the material composition, or to data capturing techniques such as radiography, magnetic particle inspection and electromagnetic waves (Volk et. al, 2014; Dai et. al, 2011), which are not considering an integrated BIM-based approach. Thus, there is lack of research which considers both, geometry and exact material determination of the existing building stock, which represents the novelty of this paper. Through coupling of laser scanning and GPR technology, the generation of MPs at the end-of-life stage of buildings will be enabled, thus delivering useful information for a digital secondary raw materials cadastre as well as for the assessment of the material value of a building.

\section{LITERATURE REVIEW AND PREVIOUS WORK}

\subsection{Circular Economy in the construction industry}

The demand for natural resources will increasingly rise due to the expected population growth up to 9 billion in 2050 (Programme des Nations Unies pour l'environnement, 2011), accordingly leading to a significant amount of waste. Therefore, one of the main future challenges will be dealing with the upcoming waste, as well as the supply of sufficient land, material and natural resources. The construction sector is the largest consumer of raw materials, with civil works and building construction being responsible for $60 \%$ of the raw materials extracted from the lithosphere (Bribián et al., 2011) as well as for $40 \%$ of energy-related $\mathrm{CO}_{2}$ emissions (Dean et al., 2016). Moreover, only 20-30\% of Construction and Demolition Waste (CDW) is recovered in the construction industry (WEF, 2016). As buildings have a long life cycle, maintenance and deconstruction management play a major role for the 
resources efficiency as well as for closed-loop cycles (Volk et al., 2014). Existing building stocks thus represent valuable material stocks, and even more - with new construction rate of $3 \%$ in Europe (Euroconstruct, 2018) - the achievement of the European Union (EU) goals 20-20-20 lies is in the existing stocks and less in new constructions. In order to minimize the consumption of raw materials, the upcoming of waste and environmental impacts, maximizing recycling rates is the main strategy, as proposed by the EU`s action plan for CE. CEs aim is to reach a resource efficient and low carbon economy by maintaining the value of materials and resources in the economy as long as possible (European Commission, 2015).

\subsection{Urban Mining}

Urban Mining is one main strategy within CE, among some others such as landfill mining and waste minimizing, dealing with mining of waste as well as with the exploration and observation of materials in the built environment, which makes Urban Mining different to usual recycling (Klinglmair and Fellner, 2010). The main obstacle, which makes Urban Mining challenging, is lack of information about materials and substances embedded in buildings (Brunner, 2011), as well as methods and tools to display the exact material composition of buildings, which would allow the prediction of future material flows as well as the increase of recycling rates. Thus, several studies were conducted, trying to determine the urban stock: Kohler and Hassler (2002) determined the material flows of the German building stock by using macroeconomic and statistical data (top-down) and coupling with bottom-up analysis of buildings, building elements and materials. In Switzerland the urban material storages were explored by using the ARK-Haus method, whereby buildings were categorized according to their age and typology (Lichtensteiger and Baccini, 2008). The "Christian Doppler Lab for Anthropogenic Resources" at Vienna University of Technology used a similar method, in order to analyse buildings and infrastructures in terms of recyclability (Kleemann et al. 2016). However, the described studies are insufficient regarding exact material composition and therefore can only give a general information about the existing stock, which is not enough to build up a secondary raw materials cadastre.

\subsection{As-built BIM}

In order to obtain an existing buildings' dimensions, currently, mostly laser scanning technology is applied (Hajian and Becerik-Gerber, 2010). Research is mainly focused on capturing the geometric representation for further processing of the obtained point cloud in BIM software (Mill et. al, 2013; Diaz et al., 2013). During the BIMgeneration process, first, the point cloud data is registered and merged into the same coordinate system (same zero point) for further point reduction by cleaning the point cloud from noise, clutter and irrelevant information. Further, the captured point cloud is used to recognize building components and to generate the BIM-elements. The generated point cloud can be converted into triangular surfaces, which however cannot be transformed directly into BIM objects. When modelling the BIM, the following issues have to be solved (Tang et. al, 2013): 1) the geometry of the components must be defined ("which shape does the wall have?"); 2) categories and materials have to be assigned to the components ("this is a brick wall."); and 3) relationships and connections between the objects must be established ("wall 1 is connected to wall 2 and is located here"). The current state of the art for generating as-built BIM-models from point clouds is still a mainly manual, time-consuming, cost-sensitive and error-prone process. A fully automated BIM modelling process or transformation of surface models into volumetric, semantically rich models is still in the beginning stage (Yang et al., 2016).

\subsection{BIM at the end-of-life stage of buildings}

At the end of the life cycle, at the demolition of an object, stands the waste management. The demolition of a building leads to a large amount and different types of solid waste. Since buildings are confronted with various changes throughout their life-cycle (renovation, thermal retrofitting etc.), it is difficult to identify the type and location of the materials within a building. Moreover, for most of the buildings the original building documentation does not exist. Accordingly, it is difficult to make assumptions about the quantity of demolition waste, as well as to enable recycling or reuse of materials, without having accurate information (Cheng and Ma, 2013). Therefore, the end-of-life stage of a building would benefit from a data model with wealth of information. BIM has the potential to serve as knowledge database and design optimization tool (Bazjanac, 2006), since it enables detailed modelling of building elements including their material composition as well as mass and quantity determination (Azhar, 2011). BIM is a shared knowledge resource consisting of information about a facility, representing a basis for decisions throughout the whole life-cycle from the conceptual phase to the demolition of a facility 
(buildingSMART, 2019). Moreover, BIM shows large capacity regarding process-automation and data management (Sebastian, 2011). As current research shows, BIM is becoming an emergent research topic for construction and demolition (C\&D) waste estimation and management (Ge et al., 2017). Rajendran and Gomez (2012) point out, that there is growing interest in the use of BIM for waste reduction as well as for design for deconstruction concepts, underlining the extensive advantages of BIM in the resource management. Hamidi et al. (2014) focused on the potentials of BIM for cost-benefit analysis of demolition waste management. Park et al. (2014) developed a demolition waste database system with BIM-based materials, by analysing the construction material classification system and data available in specific BIM-software.

The challenge for using BIM technologies lies especially in digitizing the current building stock and thereby making it accessible to the life cycle orientated management in accordance with the BIM philosophy. In order to use BIM-models for resources efficiency, comprehensive information on the geometry and materials of buildings is required and needs to be embedded in the BIM-model. As Brunner (2011) highlighted, lack of information on the material composition of buildings is the main obstacle for Urban Mining. However, identifying the type and location of materials embedded in buildings is a challenging task (Cheng and Ma 2013).

\subsection{Material identification}

Although there are already numerous methods and technologies for capturing of existing facilities, these focus mostly on the gathering of geometry - the gathering of the material composition is currently little explored. Previous research is limited to image-based material recognition, which builds upon distinguishable visual features of different materials (Yang et al., 2016). Some preliminary work was carried out by Brilakis et al. (2005), where a recognition of construction materials within image content was tested and validated. Son et al. (2012) focused on material identification with machine learning algorithms for concrete structural component detection. Material recognition through $3 \mathrm{D}$ point clouds is confronted with obstacles due to the non-smooth nature of the points colour and the irregular distribution of 3D points (Kim et al., 2011). In Austria, pre-demolition audits are conducted to assess the waste masses of material as well as to detect hazardous materials e.g. asbestos, since they require a special demolition and disposal procedure (ÖNORM EN ISO 16000-32, 2014). However, the information is not sufficient, since it is gathered by knocking and relies on assumptions. The main disadvantage of image-based material recognition is, that only the surface material is identified. Accordingly, the information is not sufficient for a MP or for waste management, since many building components such as walls and slab comprise of multilayered constructions. Terahertz spectroscopy is a promissing non-destructive method for material recognition beyond surface, which did not find a broad application in the AEC-industry yet, as it is mainly used for pharmaceutical products and biological tissues, such that it delivers results on small-scale (trace mineral) (Abina et al., 2015). Data capturing techniques such ground penetrating radars (GPR), radiography, magnetic particle inspection, sonars or electro-magnetic waves, are promising structure recognition methods beyond surface, but were not explored yet (Volk et al., 2014; Dai et. al, 2011). Lu et al. (2020) followed a BIM-based approach by integration of image-based material information into an IFC (Industry Foundation Classes) - model, which is a standardized digital description of a building (buildingSMART, 2019). However, this research is also based on image-based material recognition.

Within this paper, Ground Penetrating Radar (GPR) technology is used for material identification, which enables a non-destructive characterization of the material composition of building components (Trinks et al., 2018). GPR is a near-surface geophysical tool which is applied for multiple purposes ranging from geological studies and geotechnical engineering to environmental contamination and biomonitoring (Zhao et al., 2013). Through the GPR, a non-destructive characterization of shallow subsurface targets is enabled, based on changes in the electromagnetic properties of the materials (Davis and Annan, 1989).

\subsection{Material Passports}

MPs, as described by the EU-wide Horizon 2020 project, are an electronic set of data that provide the necessary information about materials, products and components for circular use (BAMB, 2019). Buildings as Material Banks (BAMB) brought practice and academia together in order to create CE solutions. The consortium aimed to implement CE strategies into the AEC industry in order to reduce waste and use fewer virgin materials. Madaster, an independent public platform, defines MP as a digital document that records the identity of all incorporated construction materials, by documenting the products and raw materials used in a building or project. The overall 
aim of Madaster is to reduce waste by providing materials with an identity (Madaster, 2019). MPs can also serve as basis for the accurate estimation of waste quantity at the end-of-life stage of a building, which is critical for demolition decision programs, waste management and logistics scheduling (Ge et al., 2017).

As the aim of this paper, is to generate a MP-suitable BIM-model for an existing building, the methodology developed for BIM-based MPs (Honic et al., 2019) partly serves as basis for this paper. The applied capturing methods (laser scanning and GPR) enable a very elaborate and comprehensive data collection, as well as the generation of information rich BIM-models, which have potential to be used for MPs as well as basis for a secondary raw materials cadastre.

\subsection{Previous work on BIM-based Material Passports}

In our previous research we developed a BIM-based MP, which documents the material composition of a building (Honic et al., 2019). The MP serves as a planning and optimization tool even in early planning phases with regard to the efficient use of materials and subsequent demolition, as documentation for the recycling of buildings and as the basis for a digital secondary raw materials cadastre at city level. The concept and content for the MP as well as the workflow for the semi-automated generation of BIM-based MPs has been developed in our previous work which is of high relevance for the current research, since the MP generation method as well as the required data for compiling a MP was investigated.

In this paper it will be demonstrated, what kind of information has to be embedded in a BIM-model, in order to be able to generate a MP for an existing building. Thereby the focus lies on data gathering and coupling of digital tools, as well as generation of a BIM-model, which fulfils the requirements for the follow-up generation of an MP. Since for existing buildings it is difficult to obtain the information on the material composition, various data gathering methods were applied in order to gather MP-relevant data. The parameters relevant for the MP were defined within the previous research project, and the workflow was tested, which is applied in this paper. The workflow is based on coupling of digital tools as well as eco-databases (Honic et al., 2019). The used tools are the BIM-tool Archicad 21 (Graphisoft Archicad 21) and MS Excel. For the integration of eco-indicators, which are required for the generation of an MP, the Austrian database IBO is used (IBO, 2019). The BIM-tool is used for modelling of the building and the material inventory and analysis tool for data management and integration of MPrelevant data from eco-databases. In MS Excel the attribution of individual layers (with, for example data relevant for recycling) is conducted, as well as the gathering of relevant information for the generation of the MP. Relevant information for the MP is the recycling potential, Global Warming Potential (GWP) and density, which are both obtained from the IBO-database as well as the required information from the BIM-model such as the volumes, thicknesses and names of each material. Through linking the information from BIM, with the MP-relevant data, including the quality of materials in MS Excel, the MP assessment is conducted. The main result of the MP (Fig. 1 ) is the recycling potential, the total material composition and the Life Cycle Assessment (ecological footprint) of the building.

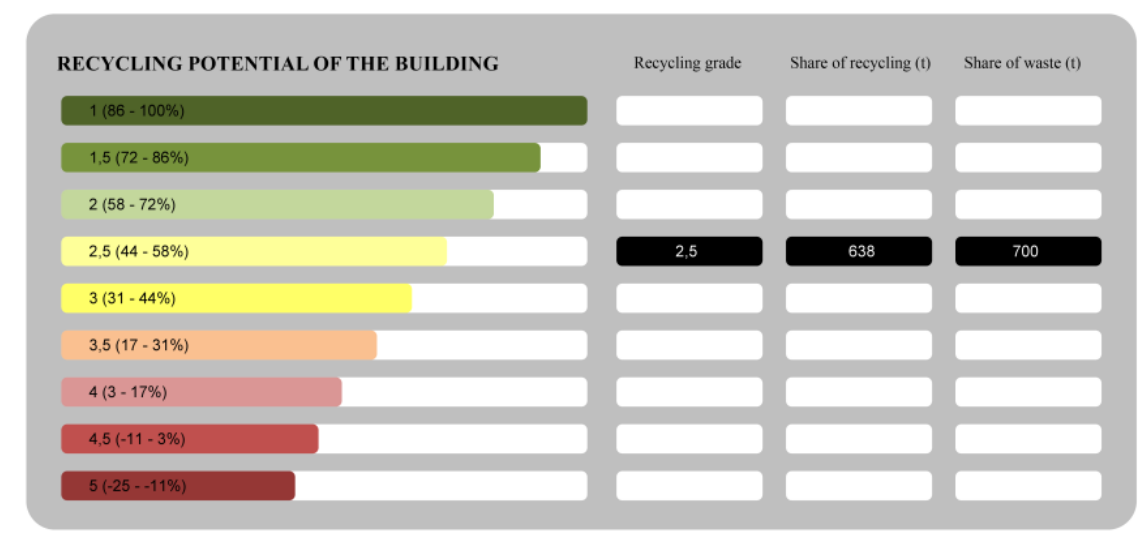

FIG 1: Example for a Material Passport, displaying Recycling-Potential of a building 


\section{METHODOLOGY}

The computational methods for the assessment of building geometry (laser scanning, photogrammetry) are well developed and mature; however, methods for material assessment are still in its beginnings. Nevertheless, other methodologies are using same data models: point cloud and BIM, which offers large potentials for synergies and creation of BIM for lifecycle models.

The methodological approach of this research is based on coupling of laser scanning and GPR technology in order to obtain one single source of information - a BIM-model. In this paper, the end-of-life stage of the building is targeted, where the MP acts as inventory by providing the exact information about the incorporated materials within a building, as well as their quality, thus serving as basis for the generation of a digital secondary raw materials cadastre and for waste management. Previous work has mainly considered the generation of as-built BIM-models based on data capturing with focus on the geometry. Current research regarding gathering of material information relies on image-based material recognition, which only delivers information about the surface materials of building elements. Lu et al. (2020) propose an integrated, BIM-based approach by considering the geometry and material. However, this work is limited to image-based material recognition.

Therefore, we propose the IDAM method based on digital scanning and modelling technologies. Through coupling of GPR technology for capturing the material composition of the building with laser scanning technology for geometry acquisition; thus, enabling a generation of as built BIM-models from acquired point clouds and nongeometric data. Capturing the material composition and geometry of existing buildings enables the creation of information rich as-built BIM-models (digital twins), as well as the automated generation of MPs, as documents of the material composition of buildings, needed for the realization of CE strategies as well as for waste management. In comparison to the state of the art as-built BIM-modelling, the IDAM method includes capturing of the material composition of existing buildings and integrating the gathered data into the as-built BIM-model via unique element IDs (Fig. 2). Accordingly, a single source of information is generated, enabling the compilation of MPs with minimum effort and the planning of the end-of-life stage of buildings.

In order to test the IDAM method, the proposed concept will be tested on a real use case. The usability-potentials of the IDAM method to serve as basis for BIM-based MPs will be evaluated.

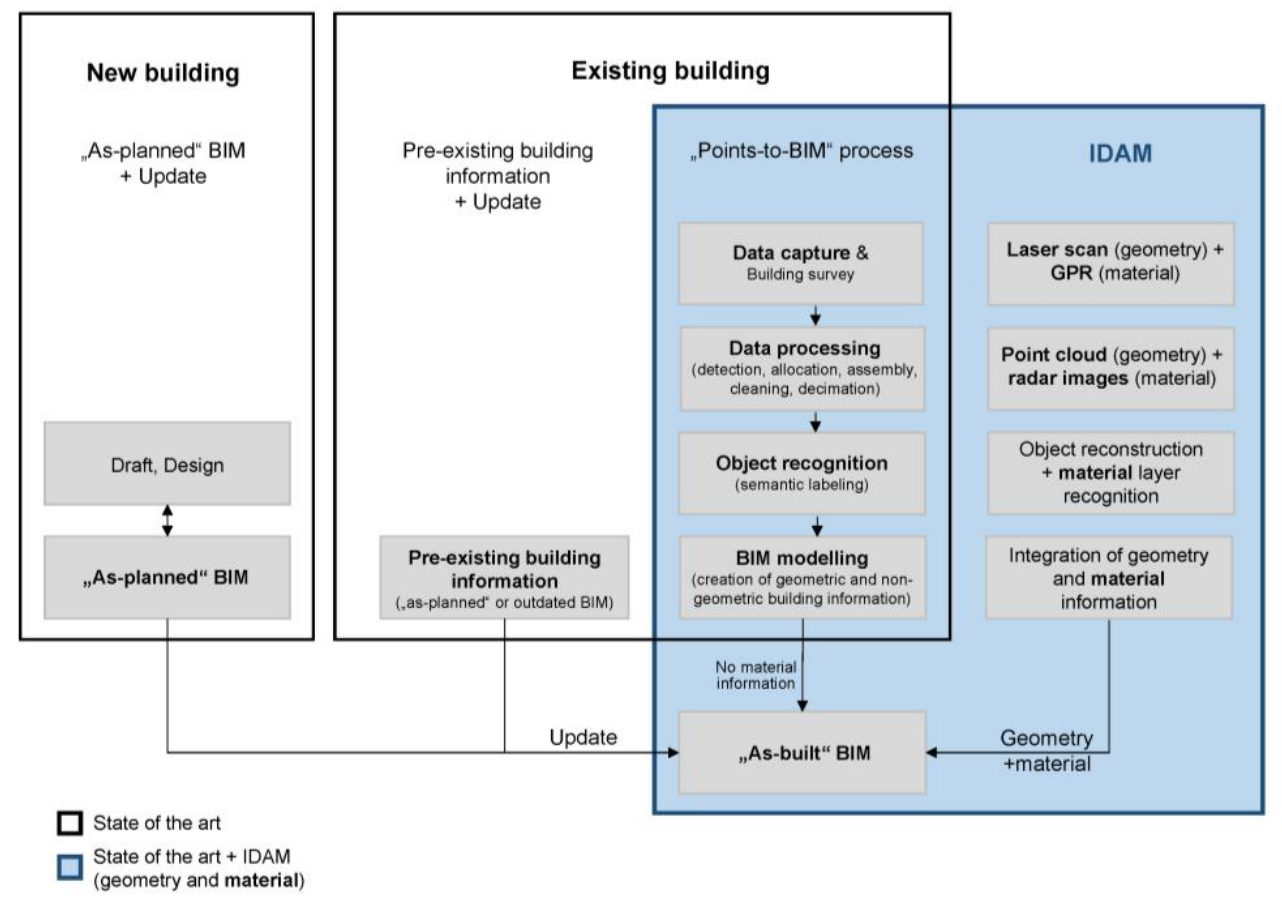

FIG. 2: Comparison of the State of the art "As-built BIM" data processing and SCI_BIM Integrated Data Assessment and Modelling method (based on Huber et al., 2011 and Volk et al., 2014) 


\section{PROOF OF CONCEPT}

\subsection{Use Case}

In order to deliver a proof of concept for the proposed Integrated Assessment and Modelling method, a real case was used - an office and lab facility of Vienna University of Technology, situated in the third district of Vienna. The use case, with a total area of $1265 \mathrm{~m}^{2}$ (Fig. 3), is a single-storey building and comprises of 3 areas: office, lab and storage area. The three areas can also be distinguished from outside due to their varying heights. The facility has a length of $\sim 62 \mathrm{~m}$ and a width of $\sim 24 \mathrm{~m}$ (on the widest side). The storage area is located in the highest part of the building, which has a height of $6.85 \mathrm{~m}$. The offices are situated in the lowest part of the building $(3.8 \mathrm{~m})$. The lab, which is attached to the storage area as well as the office area, has a height of $6 \mathrm{~m}$.

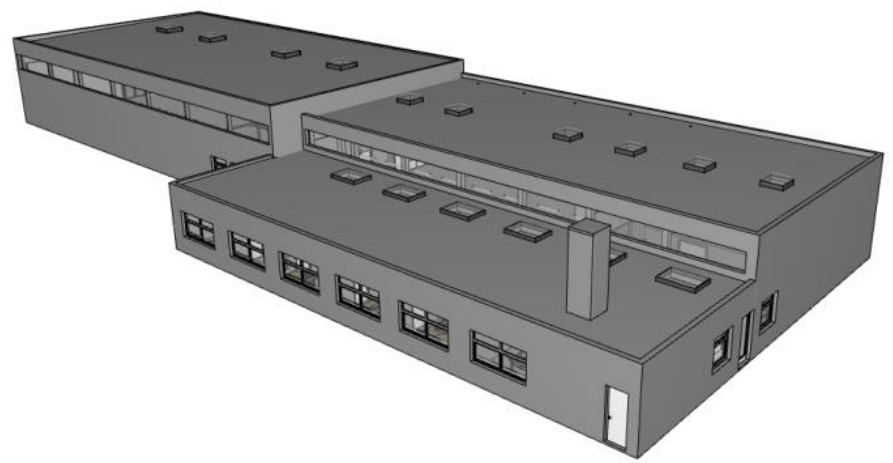

FIG 3: BIM-model of the use case, as generated by company 1

\subsection{Data acquisition}

Data acquisition was conducted by two surveying companies $(\mathrm{C} 1, \mathrm{C} 2)$ and a research institute (C3). The building was scanned with different devices for geometry (high- and low tech) and material acquisition (GPR). For the high-tech data acquisition, a handheld scanner (GeoSLAM) was used, which delivers a high-resolution point cloud. The low-tech variant is based on a low-cost terrestrial laser scanner. As the high-tech variant delivers more accurate results, it was chosen as the reference model. All results shown in this paper build up on the high-tech variant. At the beginning of data acquisition at the building, it was occupied by the users, which made the scanning tasks difficult due to the users as well as the furniture within the building. Since the use case was a demolition object, the users moved out of the building, which enabled scanning of each building component. Figure 4 displays the panorama of the use case, which was taken by the laser scanner camera. In total, the building has been scanned multiple times with laser scanners (handheld scanner) as well as with GPR from inside and outside. The capturing of the entire building with the high-tech method, required 4 scans and took 2 hours. Scans via ground penetrating radar (GPR) were conducted on three different days and took about 20 hours. The GPR is currently the most efficient geophysical method for the appropriate assessment of multi-layered building components and thus offers potential for the digital recording of the material composition. The building elements (walls and floors) were scanned with the GPR device, which is a small device that is being hold on the wall or floor (see Fig. 5). Most of the walls were measured on three varying heights (bottom, top and in between at a height of $1.1 \mathrm{~m}$ ) horizontally. Following a horizontal line, a measurement was taken every centimeter. Measurements are performed by sending electromagnetic waves to building elements, which are radiated into the element by a transmitting antenna. Thereby the wave diffuses in the wall with a material-dependent speed and is reflected at the interfaces of individual objects or from layers of different physical properties (permittivity, conductivity). The electromagnetic signal returning to the surface is captured by a receiver antenna and is recorded digitally. The recorded data was analysed, which enabled to differentiate between various materials within building elements. A pre-demolition audit was conducted, as it is required in Austria, in order to identify the material composition as well as the quality of the materials (harmful and or contaminant materials) incorporated in the building, which is necessary in order to define the recycling potential of the materials. 
The scan-to-BIM process was conducted in a twofold way: through an automated and manual generation of the BIM-Model, for the purpose of comparison and evaluation of both methods. Since the automated BIM-model generation is not the focus of this paper, only the manual generation of the BIM-model will be described in detail. Laser scanning of the entire building enabled the generation of the point cloud (Fig.6 and Fig. 7), which was postprocessed in PointCab (PointCab, 2019) for point reduction. The post-processed point cloud was imported in the BIM Software Archicad, where, based on horizontal sections, the BIM-model was generated manually by inserting mono-layered building objects such as walls or slabs. As a result, a BIM-model with mono-layered elements, without any material information, was generated.

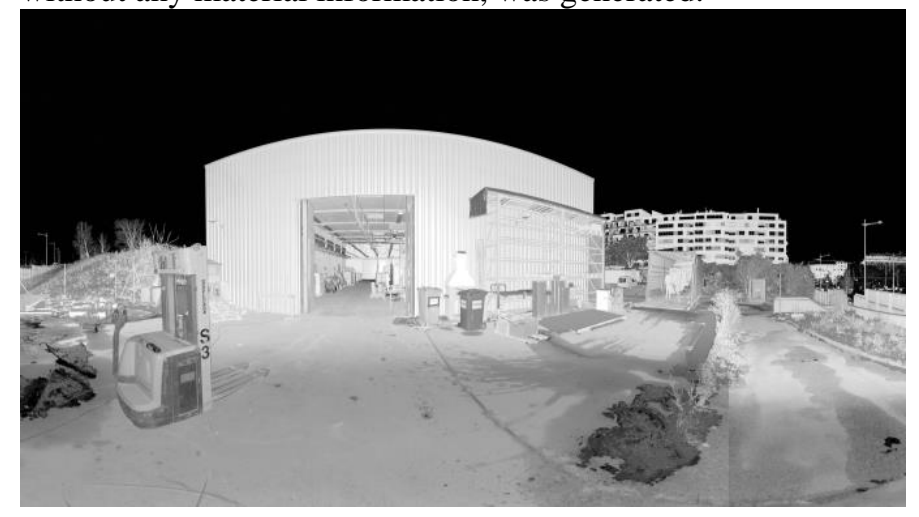

FIG 4: Panorama of the use case by laser scanner camera, as generated by company 1

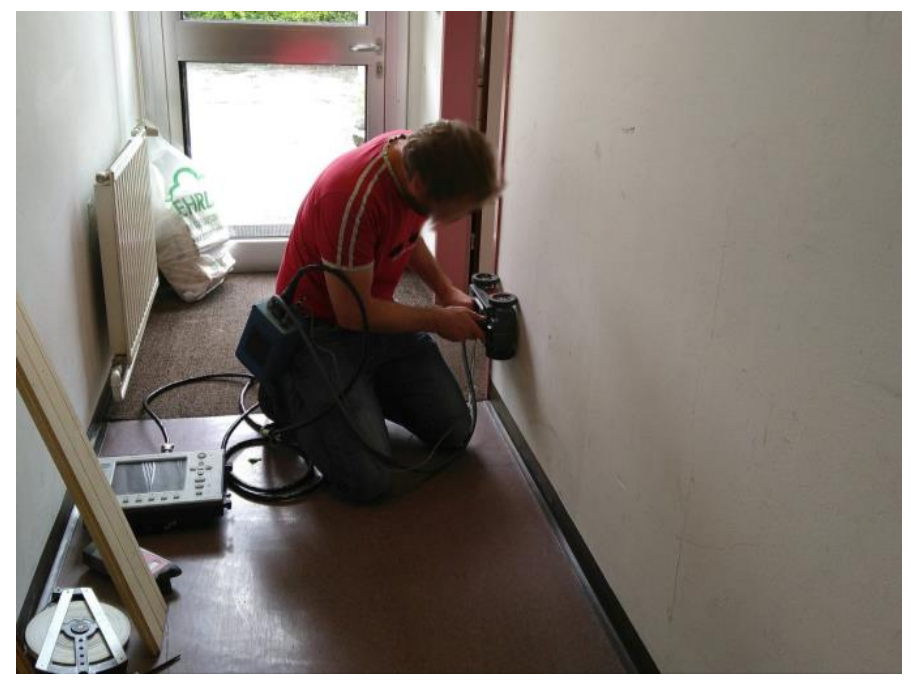

FIG 5: GPR scan of an interior wall, as generated by ZAMG Archeo Prospections

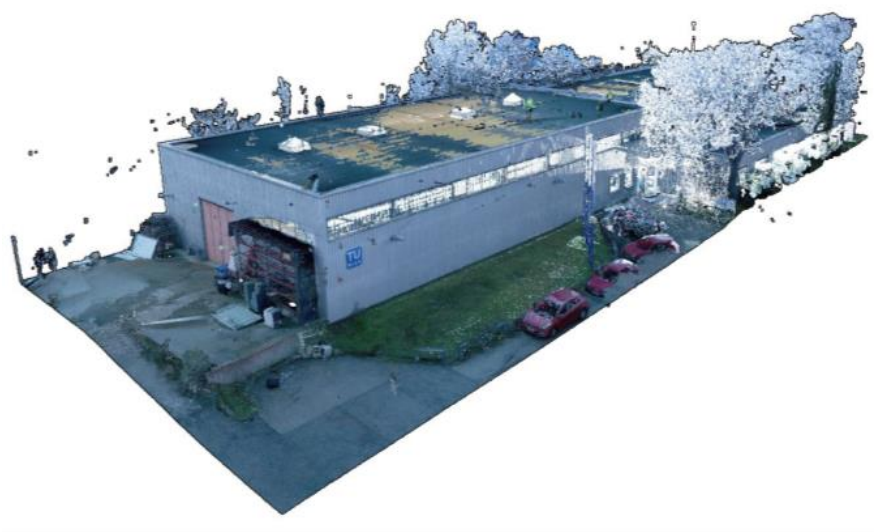

FIG 6: Point Cloud 1 from laser scan of the use case, as generated by company 1 


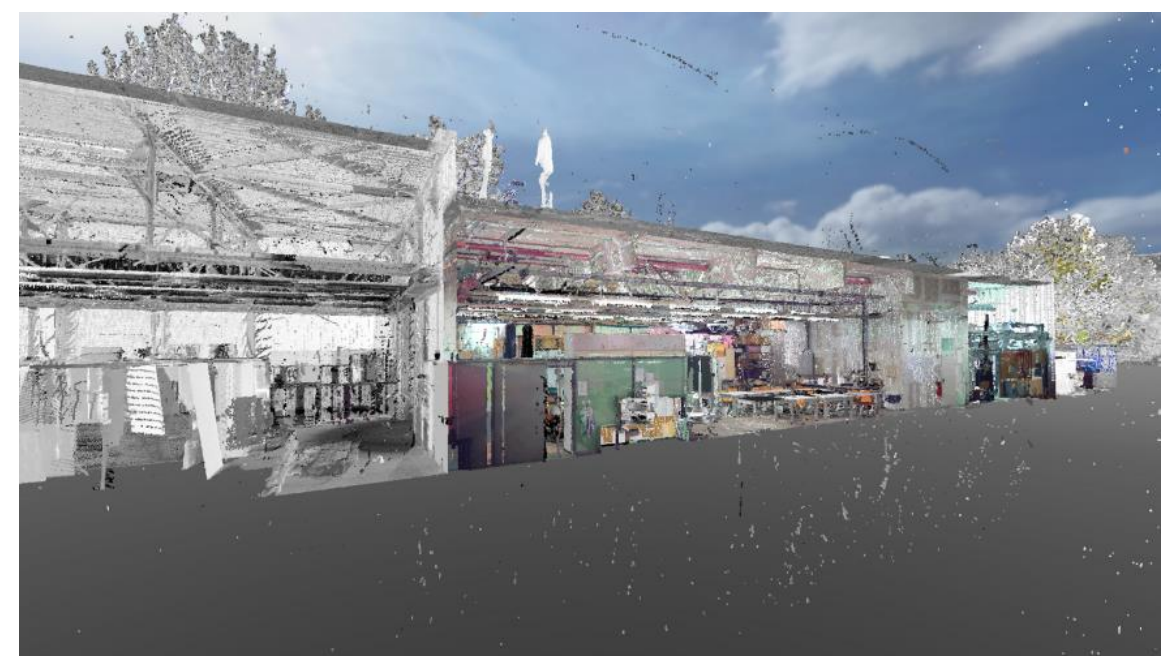

FIG 7: Point Cloud 2 from laser scan of the use case, as generated by company 1

\subsection{Evaluation of GPR-technology for material assessment and identification}

The GPR measurements were conducted by sending electromagnetic waves and measuring the changes in the signal form (amplitude and frequency). The changes in the signal form allowed conclusions about the physical properties of the irradiated components, such as their mineral composition, moisture, porosity, etc. The electromagnetic energy radiated into the walls is damped differently depending on the component (material-related absorption loss). By comparing the amplitudes of the transmitted and received electromagnetic waves, it was possible to determine the absorption properties of the materials. Thus, conclusions of different materials within the building elements were possible.

GPR showed large potential for the identification of materials within building elements, but was confronted with various difficulties such as furniture and users of the building. Moreover, the exterior walls consist of a metal sheet cladding, through which the GPR cannot penetrate. However, the GPR can only detect different materials due to their varying physical properties (permittivity, conductivity) but cannot determine the material compositions immediately. Therefore, an interpretation of the acquired data was necessary in order to make assumptions on the exact material composition of building elements. Accordingly, the information on the material composition from the pre-demolition audit was also considered. By comparison of the measured data (from the GPR) and the information from the state-of-the-art pre-demolition audit, as well as through calibration of the acquired information, the material composition was determined as exact as possible. However, some of the results were ambiguous, which required further analysis at the use case. Fig. 8 shows the first results of the GPR-scans where e.g. concrete walls (exterior walls, in Fig. 8 they are black) and plasterboard walls (interior walls, in Fig. 8 they are green) could be differentiated excellently. Each building element is referenced to the BIM-model through the element ID, which enabled the integration of the materials in the reference BIM-model. The integration of the materials information required a generation of multi-layered elements within BIM-software, based on the obtained information on the material composition, as well as the thicknesses of each layer, from the GPR. The generated multi-layered elements were assigned to the elements of the reference BIM-model by following the IDs. As the thicknesses of the elements within the reference BIM-model and the generated multi-layered elements did not match for each element, some optimization was conducted. An automated integration of materials information in the BIM-model is not possible yet. The main obstacle in the integration of materials information into the reference BIM-model was, that the BIM-model and material model (results of GPR) did not always fit together: Some walls consisted of two different material compositions, as the results of the GPR showed, but were modelled as one element in the BIM-model, since from outside the building element appeared as one wall. In order to overcome this obstacle, the elements were separated in the BIM-model for follow-up integration of the materials information. Another problem occurred due to technological restrictions of the GPR: the GPR can only recognize element with more than $6 \mathrm{~cm}$ thickness. This means, that for many building elements, the first layer was not recognized by the GPR, which required a manual step of identification of the materials of the entire element, by checking the analysis conducted by the demolition expert. 


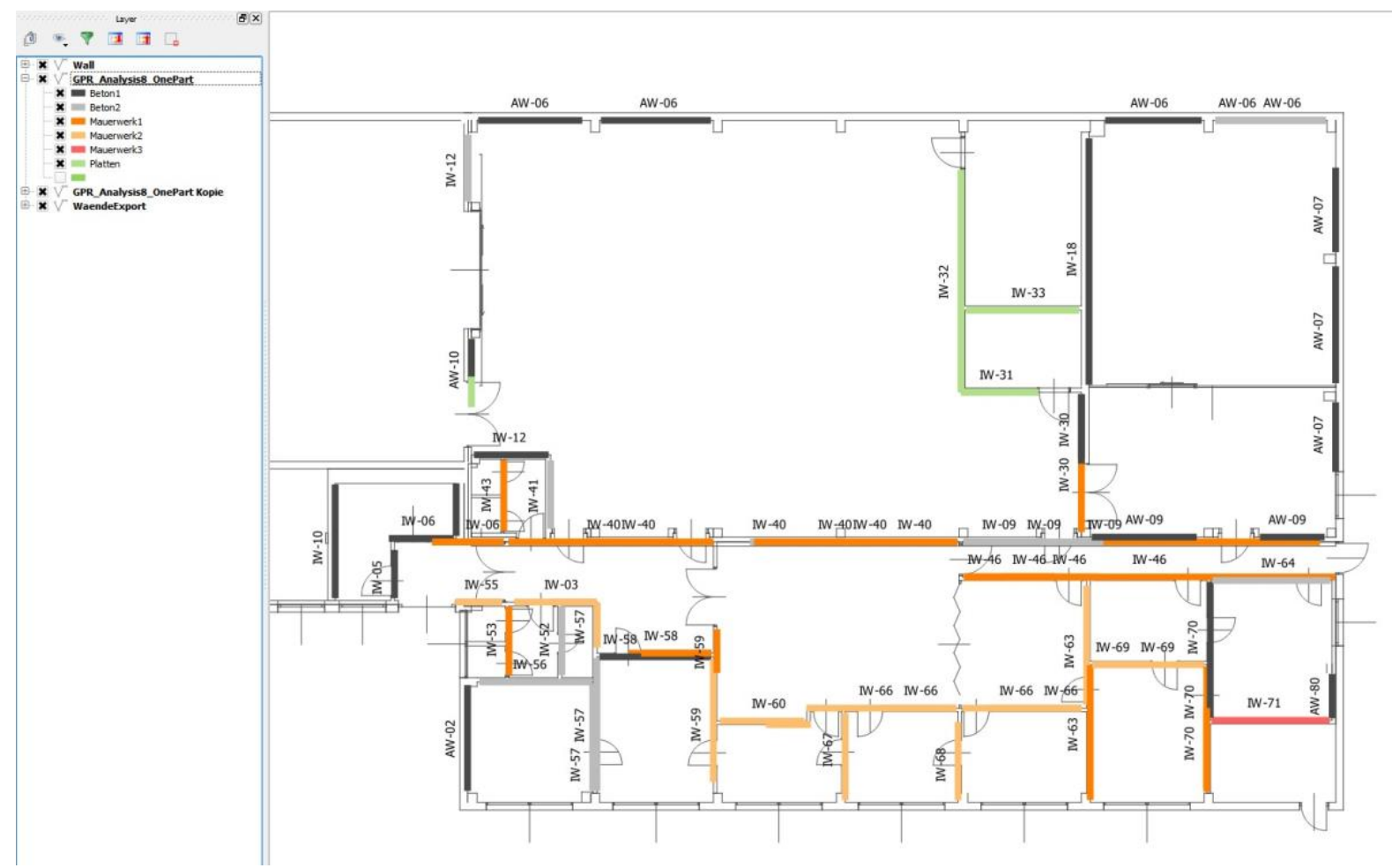

FIG 8: Results of the GPR-scan, as generated by ZAMG Archeo Prospections

\section{FRAMEWORK PROPOSAL: IDAM FOR BIM-BASED MATERIAL PASSPORTS}

Through experiences gathered within the use case, a framework including automation potentials and nodal points for automation algorithms was proposed (Fig. 9). The method is based on the handheld scanning technology for capturing of geometry and post-processing of the point-cloud, as well as on GPR for material capture. By using the referential BIM-model, where all building elements are classified via customised IDs (e.g. AW01 - exterior wall type 1), linking of the material-assessment of particular elements via ID to the referential model is enabled.

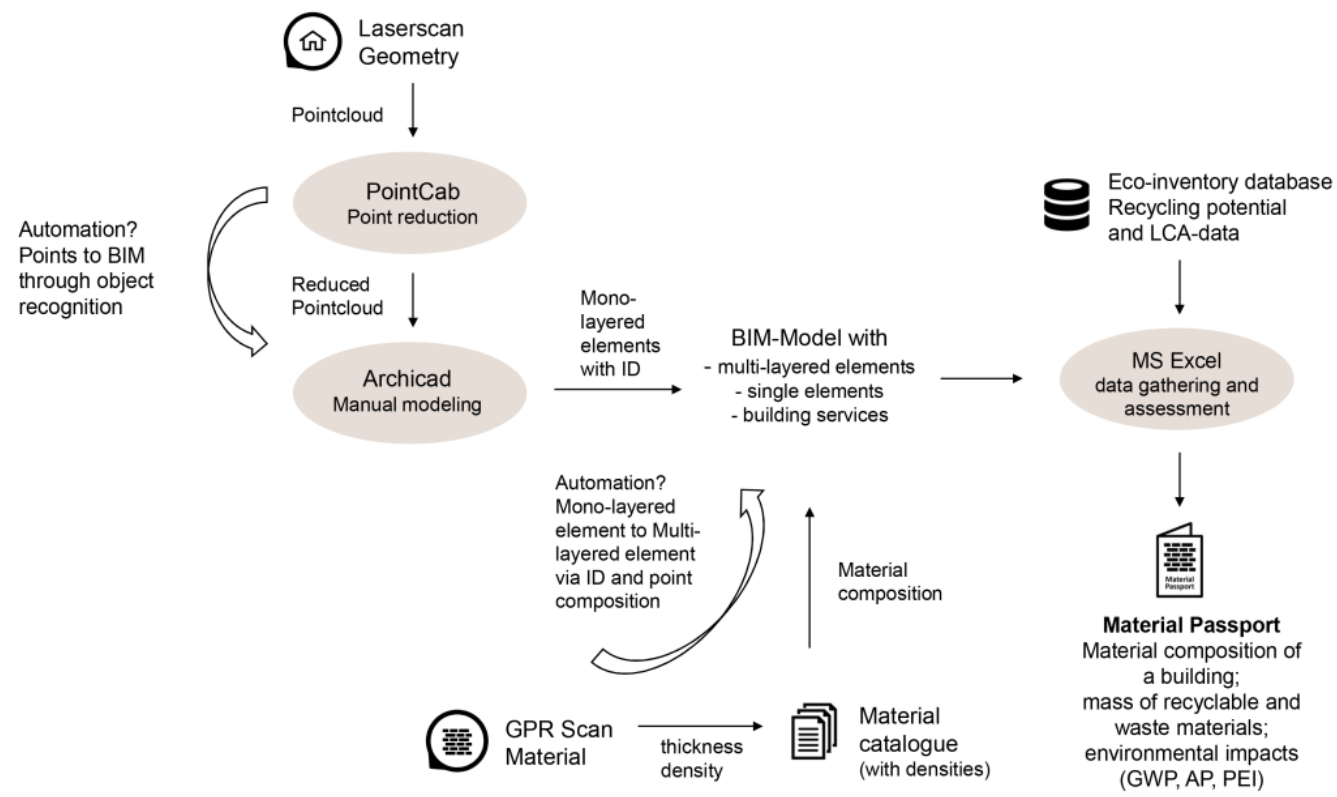

Figure 9: Framework-Proposal for Integrated Assessment and Modelling Method for MPs 
The BIM-model, enriched with material information, allows a semi-automated compilation of the MPs, by exporting an element list from BIM and linking data from eco-inventories in order to assess e.g. the recycling potential of the building. As preliminary result, an MP-suitable BIM-model was generated, which enables the follow-up generation of a MP. However, the BIM-model still requires some optimization, since some walls need to be split into two pieces, due to their varying material composition, and the corresponding materials information integrated (see section 5.1). Further automation potential is automated integration of multi-layered elements based on the obtained materials' information and the elements' IDs. The proposed framework can serve as basis for follow-up research as well as for the optimization of the applied method.

\section{DISCUSSION}

In this paper the novel IDAM method was presented, integrating potentials of the combined application of laser scanning and GPR for the generation of a BIM-model, serving as basis for the follow-up generation of a BIMbased MPs.

The individual technologies and digital tools used in this research are well researched and established in the respective field: GPR for the detection of structures near-ground in archaeology or for geological soil surveys, building capturing and measurement through laser scanning and creation of the BIM geometry models from the point cloud, but the use of these technologies to capture and model the material composition of the single object or even the building stock is still largely unexplored. The integration of modelling approaches and generation of as built BIMs for the generation of MPs thus contributes to the optimization of resources efficiency at the level of single objects as well as at city level, and thus to technical and procedural innovation.

Laser scanning and GPR technology was applied on a real use case, in order to determine the geometry and the material composition of the building and to generate an as built BIM-model. Laser scanning is an established data acquisition method, whereas the use of the GPR represents a novelty, since it was originally developed for geological assessments. The conducted research on the use case has demonstrated, that the scanning of assets in occupied state represents a particular challenge. For the GPR application especially the furniture and fixtures represented an obstacle. Further, the users often felt disturbed by scanning in their daily working routines. Thereby close cooperation of the researchers with the users and occupants is needed in order to overcome these challenges. However, this problem was solved when the users of the building moved out and the building was cleared out. The GPR showed large potential in the determination of the material composition of building elements, however was confronted with various obstacles and needs further optimization and automation regarding integration of the materials information in the BIM-model. The GPR could not identify the materials within a building element immediately, but required a further step of interpretation of the GPR measurements as well as a comparison of the real material composition, which was defined by the pre-demolition audit, with the GPR measurements. However, some of the results from the demolition expert and the GPR measurement were ambiguous, which required further analysis at the use case. Through calibration of the measurements, the final material composition was determined. The integration of the materials information in the BIM-model, generated with a scan-to-BIM approach, was enabled through element IDs. Since the mapping of the elements within the GPR measurement were based on the reference BIM-model, which consisted of element IDs, the identification of the elements did not lead to any issues. However, the automated integration of the materials information into the BIM-model was not realized yet. The valuable advantage of GPR technology, is the non-deconstructive detection of building materials, as well as the accuracy of the gathered materials information. The GPR can also detect cables and pipes within building elements, which can be valuable resources with high recycling potential, if they are out of metal material. Such an accuracy is not possible with the state-of-the-art material identification through a pre-demolition audit, which is mainly conducted by knocking, drilling and is based on assumptions and random samples.

A framework including automation potentials and nodal points for automation algorithms was proposed based on the knowledge gained through the use case. Within the framework the method for the generation of a BIM-model based on the acquired data from laser scanning and GPR for follow-up generation of MPs is presented, which can serve as basis for follow-up research. 


\section{CONCLUSION AND FUTURE OUTLOOK}

The applied technologies - laser scanning and GPR- for the generation of an as built BIM including material information, showed large potential, but need further improvement regarding automated integration of materials information into the BIM-model as well as automated detection of materials within building elements. The real use case can be seen as a particular strength of the present research, since the development and testing of the assessment methods on real objects enables capturing of multiple perspectives of all stakeholders and guarantees for verified results, which is not possible when working only with models or fictitious use cases. Moreover, the rather small size of the building and the fact, that it was a single-storey building, represented an advantage regarding effort during data gathering. However, the building is not representative for buildings in Vienna, since the construction is typical for industrial buildings, but not for housing, which represents $80 \%$ of the Viennese stock.

The insufficient automated data transfer from one process step to the next, as well as insufficient data structuring, which would allow a fluently data transfer, is one of the major obstacles to the full exploitation of the BIM potential as a knowledge base for further analysis and optimization, such as material and life cycle assessment. The intended improvements should be made by automated workflows and automated data transfer in BIM significantly speeds up common planning, analysis, and optimization processes, as manual modelling, which is currently state of the art, is time-consuming and error-prone. An automated data transfer is tested within the research project SCI_BIM, by using IFC, which is an open, international standard. Thereby, a semi-automated IFC-model from the point cloud is generated and in a further step the GPR-results integrated automatically into the IFC-model. However, the results of the automated integration of the material information is not finalized yet. Apart from that, a concept which enables the assessment of changes on buildings through the commitment of users based on gamification, was developed for the maintenance of the BIM-model within the research project. This innovative gamification concept allows assessment of the structural changes (users scan QR-codes via smartphone which are applied on building elements and are linked to the BIM-model via IDs) which are uploaded in the as-built BIM within the gamification platform and of user behaviour (such as open windows or lighting) through user participation. Through implementation of user data, the as-built BIM is updated. The gamification would on the one hand enable capturing of structural changes (static data), which are relevant for the MP and on the other, compilation of a user behaviour model (dynamic), which can serve as basis for optimizing the energy efficiency of the building. A cost-efficiency analysis of the used methods and devices is also conducted within the project, in order to determine the most efficient way to generate a BIM-model suitable for MPs. Within the cost-efficiency analysis also the time-effort, costs for personnel and devices, as well as the quality of the obtained models are assessed. As SCI_BIM is still ongoing, the results are not finished yet.

The research has demonstrated that the conducted assessment method for the material composition of the building is associated with large effort, due to its novelty in the building sector as well as lack of existing datasets generated by the GPR (material identification). A broader application of the GPR-technology on various buildings could enable an automated detection of materials through comparison of obtained data with the real material composition as well as through applying Machine Learning technology. Therefore, it is necessary to build up a material database with typical building elements, which represent the training data set of Machine Learning. Thus, the future outlook is the development of Machine Learning algorithms for the automated and non-destructive recognition of multilayered building elements in existing buildings. The gathered knowledge on the material composition of the existing could enable the creation of a digital secondary raw materials cadastre for the city of Vienna. The existence of such a cadastre would enable the assessment, analysis and prediction of the material flow, as well as increase of the recycling potential of the building stock, thus supporting the EU`s action plan for Circular Economy.

\section{ACKNOWLEDGEMENTS}

The authors would like to acknowledge the support by the Austrian funding institution FFG (Österreichische Forschungsförderungsgesellschaft) for the research project "SCI_BIM" (Grant No. 867314). The authors would also like to acknowledge the industrial partners RM Umweltkonsulenten ZT GmbH and Meixner Vermessung ZT $\mathrm{GmbH}$ as well as the research partner ZAMG Archeo Prospections, through which the conduction of this research was enabled. 


\section{REFERENCES}

Azhar S. (2011). Building information modeling (BIM): Trends, benefits, risks, and challenges for the AEC industry, Leadership and management in engineering, Vol. 11, No. 3, 241-252.

BAMB. (2019). Buildings as Material Banks. Available at: https://www.bamb2020.eu/ (Accessed 12 December 2019).

Bassier, M., Yousefzadeh, M., Vergauwen, M. (2020). Comparison of 2D and 3D wall reconstruction algorithms from point cloud data for as-built BIM. Journal of Information Technology in Construction (ITcon), 25(11), 173-192.

Bazjanac, V. (2006). Virtual building environments (VBE)-applying information modeling to buildings. August, 29, 2009.

Bribián I.Z., Capilla A.V., Usón A.A. (2011). Life cycle assessment of building materials: Comparative analysis of energy and environmental impacts and evaluation of the eco-efficiency improvement potential, Building and Environment, Vol. 46, No. 5, 1133-1140.

Brilakis, I., Soibelman, L., \& Shinagawa, Y. (2005). Material-based construction site image retrieval. Journal of computing in civil engineering, 19(4), 341-355.

Brunner, P. H. (2011). Urban mining a contribution to reindustrializing the city. Journal of Industrial Ecology, Vol. 15, No. 3, 339-341.

Brunner P.H., Rechberger H. (2017). Handbook of Material Flow Analysis: For Environmental, Resource, and Waste Engineers. 2nd ed., CRC Press, New York.

buildingSMART. (2019). https://www.buildingsmart.org/ (accessed 30 October 2020).

Cheng, J. C., Won, J., \& Das, M. (2015, July). Construction and demolition waste management using BIM technology. In 23rd Ann. Conf. of the International Group for Lean Construction, Perth, Australia (pp. 381390).

Cheng, J. C., \& Ma, L. Y. (2013). A BIM-based system for demolition and renovation waste estimation and planning. Waste management, 33(6), 1539-1551.

Dai F., Lu M., Kamat V.R. (2011). Analytical approach to augmenting site photos with 3D graphics of underground infrastructure in construction engineering applications, Journal of Computing in Civil Engineering, Vol. 25, No. 1, 66-74.

Davis, J. L., Annan, A. P. (1989). Ground-penetrating radar for high-resolution mapping of soil and rock stratigraphy 1. Geophysical prospecting, 37(5), 531-551.

Dean B., Dulac J., Petrichenko K., Graham P. (2016). Towards zero-emission efficient and resilient Buildings. Global Status Report [Online]. Available at: https://www.worldgbc.org/sites/default/files/ (GABC_Global_Status_Report_V09_november_FINAL.pdf). (Accessed 12 December 2018).

Díaz-Vilariño, L., Lagüela, S., Armesto, J., \& Arias, P. (2014). Indoor daylight simulation performed on automatically generated as-built 3D models. Energy and Buildings, 68, 54-62.

Euroconstruct (2018). Construction will continue to grow in Europe. Available at: https://euroconstruct.org/ec/press/pr2018_85 (Accessed 11 June 2019).

European Commission (2015). Communication from the Commission to the European Parliament, the Council, the European Economic and Social Committee and the Committee of the Regions. Closing the Loop - An EU action plan for the Circular Economy [Online]. Available at: https://eur-lex.europa.eu/legalcontent/EN/TXT/?uri=CELEX:52015DC0614 (Accessed 12 December 2018).

Fellows, R., Liu, A. M. (2012). Managing organizational interfaces in engineering construction projects: addressing fragmentation and boundary issues across multiple interfaces. Construction management and economics, 30(8), 653-671. 
Ge, X. J., Livesey, P., Wang, J., Huang, S., He, X., Zhang, C. (2017). Deconstruction waste management through $3 \mathrm{~d}$ reconstruction and bim: a case study. Visualization in engineering, 5(1), 1-15.

Graphisoft (2017). Archicad 21 [Software]. Available at: https://www.graphisoft.com/archicad/ (Accessed 12 December 2019).

Hajian H., Becerik-Gerber B. (2010). Scan to BIM: factors affecting operational and computational errors and productivity loss, 27th International Symposium on Automation and Robotics in Construction, 265-272.

Honic M., Kovacic I., Sibenik G., Rechberger H. (2019). Data-and stakeholder management framework for the implementation of BIM-based Material Passports, Journal of Building Engineering, Vol. 23, 341-350.

Huber D., Akinci B., Oliver A.A., Anil E., Okorn B.E., Xiong X. (2011). Methods for automatically modeling and representing as-built building information models, Proceedings of the NSF CMMI Research Innovation Conference, 4-7 January, Atlanta, Georgia.

IBO (2019). Austrian Institute for Building Biology [Online]. Available at: https://www.ibo.at/ (Accessed 12 December 2019).

Kim, C., Son, H., Kim, C. (2011). The effective acquisition and processing of 3D photogrammetric data from digital photogrammetry for construction progress measurement. In Computing in civil engineering (2011) (pp. 178-185).

Kleemann, F., Lederer, J., Aschenbrenner, P., Rechberger, H., \& Fellner, J. (2016). A method for determining buildings' material composition prior to demolition. Building Research \& Information, Vol. 44, No. 1, 51-62.

Kohler, N., \& Hassler, U. (2002). The building stock as a research object. Building Research \& Information, Vol. 30, No. 4, 226-236.

Klinglmair, M., Fellner, J. (2010). Urban mining in times of raw material shortage: Copper management in Austria during World War I. Journal of Industrial Ecology, Vol. 14, No. 4, 666-679.

Lichtensteiger, T., Baccini, P. (2008). Exploration of urban stocks. Journal of Environmental Engineering and Management, Vol. 18, No. 1, 41.

Lu, Q., Chen, L., Li, S., Pitt, M. (2020). Semi-automatic geometric digital twinning for existing buildings based on images and CAD drawings. Automation in Construction, 115, 103183.

Madaster. (2019). https://www.madaster.com/en (Accessed 12 December 2019).

Mill T., Alt A., Liias R. (2013). Combined 3D building surveying techniques-terrestrial laser scanning (TLS) and total station surveying for BIM data management purposes, Journal of Civil Engineering and Management, Vol. 19, 23-32.

MS Excel. (2019). Microsoft Office. https://products.office.com/de-at/excel (accessed 02 July 2019).

PointCab (2019). [Software]. Available at: https://www.pointcab-software.com/ (Accessed 12 December 2019).

Programme des Nations Unies pour l'environnement (2011). Towards a green economy: Pathways to sustainable development and poverty eradication. United Nations Environment Programme [Online]. Available at: https://sustainabledevelopment.un.org/index.php?page=view\&type=400\&nr=126\&menu=35 (Accessed 12 December 2018).

Rajendran P., Gomez C.P. (2012). Implementing BIM for waste minimization in the construction industry: A literature review, 2nd International Conference on Management, Malaysia, 557-570.

Sebastian, R. (2011). Changing roles of the clients, architects and contractors through BIM. Engineering, construction and architectural management, 18(2), 176-187.

Tang P., Huber D., Akinci B., Lipman R., Lytle A. (2010). Automatic reconstruction of as-built building information models from laser-scanned point clouds: A review of related techniques, Automation in construction, Vol. 19, No. 7, 829-843. 
Trinks, I., Hinterleitner, A., Neubauer, W., Nau, E., Löcker, K., Wallner, M., ... \& Seren, S. (2018). Large-area high-resolution ground-penetrating radar measurements for archaeological prospection. Archaeological Prospection, 25(3), 171-195.

Volk R., Stengel J., Schultmann F. (2014). Building Information Modeling (BIM) for existing buildings Literature review and future needs, Automation in construction, Vol. 38, 109-127.

WEF. (2016). World Economic Forum. Can the circular economy transform the world's number one consumer of raw materials. In World Economic Forum. Available at: https://www.weforum.org/agenda/2016/05/canthe-circular-economy-transform-the-world-s-number-one-consumer-of-raw-materials/ (Accessed 24 February 2021).

Xiong, X., Adan, A., Akinci, B., Huber, D. (2013). Automatic creation of semantically rich 3D building models from laser scanner data. Automation in construction, 31, 325-337.

Yang, J., Shi, Z. K., Wu, Z. Y. (2016). Towards automatic generation of as-built BIM: 3D building facade modeling and material recognition from images. International Journal of Automation and Computing, 13(4), 338-349.

Zhao, W., Forte, E., Pipan, M., \& Tian, G. (2013). Ground penetrating radar (GPR) attribute analysis for archaeological prospection. Journal of Applied Geophysics, 97, 107-117. 